\title{
LA DIMENSIÓN COGNITIVA DE LAS PASIONES: \\ LA VIGENCIA DE ARISTÓTELES EN LA \\ PSICOLOGÍA MORAL CONTEMPORÁNEA
}

\author{
THE COGNITION OF PASSIONS \\ THE CONTEMPORARY RELEVANCE OF \\ THE ARISTOTELIAN THOUGHT IN MORAL \\ PSYCHOLOGY
}

\author{
Diego S. Garrocho Salcedo* \\ Universidad Autónoma de Madrid
}

RESUMEN: Nuestra tradición filosófica ha dedicado no pocos esfuerzos a desentrañar la siempre problemática relación entre la razón y las pasiones, una dicotomía que habrá de remitirnos necesariamente a los conceptos griegos de $\lambda o ́ \gamma o \varsigma$ y $\pi \alpha ́ \theta$ os. Desde William James hasta nuestros días, la ciencia ha subrayado la dimensión cognitiva de las pasiones (Lazarus) así como su necesario concurso en la construcción de ciertas categorías morales (Prinz). En línea con algunas investigaciones recientes que defienden la vigencia del pensamiento de Aristóteles en neurociencia contemporánea (e.g., D.M. Gross) en este artículo trataremos de rastrear el origen aristotélico de esta teoría dominante en la psicología actual. Para ello - y aunque ya Platón empleara categorías epistemológicas para describir el placer - proponemos examinar específicamente la relación que Aris-

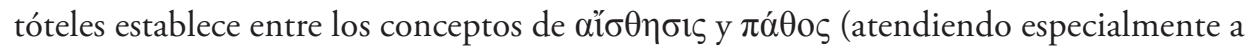
algunos pasajes de Ética Nicomáquea y De Ánima). Basándonos en estudios como los que han llevado a cabo Deborah Achtenberg, Martha Nussbaum o John M. Cooper, en este artículo trataremos de justificar la implícita vigencia de la descripción aristotélica de las pasiones en torno a tres rasgos fundamentales: su cualidad intencional, su implicación en la percepción del valor y su relevancia moral.

Palabras Clave: Aristóteles, pasiones, emociones, razón, psicología moral, cognición.

\footnotetext{
*diego.garrocho@uam.es
} 
Авsтract: Our philosophical tradition has mainly been devoted to the task of shedding light on the problematic relation between reason and passion, continuing the

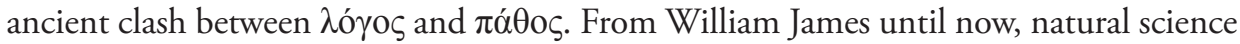
has emphasized the cognitive dimension of passions (Lazarus) and its involvement in the construction of certain moral categories (Prinz). In line with the implication, by some recent research, of the contemporary relevance of Aristotelian thought in neuroscience (D. M. Gross), this paper aims to reveal the classic roots of this paradigm. In order to achieve this goal — and fully aware of the Platonian precedents - we propose to analyze the specific link established by Aristotle between $\alpha$ î́ $\theta \eta \sigma ı \varsigma$ and $\pi \alpha \dot{\theta} \theta$ os in Nicomachean Ethics and On the Soul. Starting with the premises traced by Deborah Achtenberg, Martha Nussbaum and John M. Cooper, this paper will try to underpin the validity of Aristotelian description of passions by means of the strength of three main notions: the intentional quality of passions, the involvement of passions in the perception of moral value and their moral.

KeYwords: Aristotle, Passions, Emotions, Reason, Moral psychology, Cognition.

\section{Introducción}

Toda persona que se dedique profesionalmente a la filosofía parece estar socialmente obligada a legitimar su tarea. Si además su investigación se concentra en el estudio de algún autor clásico se hace imprescindible apelar a la vigencia o utilidad contemporánea del filósofo en cuestión. La filosofía es exigida conforme a criterios de utilidad y rentabilidad y el estudioso, académico o incluso el aficionado se encuentra siempre forzado a legitimar su profesión o vocación. La filosofía fue y acaso será una actividad bajo sospecha, una sospecha de la que afortunada o desafortunadamente la literatura quedó históricamente eximida tal vez porque, como dijera Nietzsche y ya muchos siglos antes Luciano, el arte no tiene ninguna vocación de verdad. Como en el cuento de Borges «Kafka y sus precursores» el erudito trata de rastrear influencias pretéritas en las prácticas discursivas contemporáneas para justificar la relevancia de su estudio. Tales, Platón, Epicteto... se describen siempre como antecedentes o precursores de filosofías actuales y el pensamiento de Aristóteles o Epicuro son interpretados en ocasiones como instrumentos eficaces para afrontar un dilema contemporáneo. El abuso de este instinto legitimador de lo griego o lo romano nos ha hecho convertir a los clásicos en antecedes causales de toda la historia posterior y ha servido para caracterizar a los antiguos filósofos como geniales precursores que ya adelantaron in nuce cualquier contenido de nuestra tradición. Por todos es conocida la cita de Whitehead: «la manera más segura de caracterizar a la tradición filosófica 
europea es como una serie de notas al pie a la filosofía de Platón» $(1979,39)^{1}$. Lo exagerado de esta sentencia se mitiga generalmente incluyendo, naturalmente, a la filosofía aristotélica.

Si hay un autor del que en ocasiones ha podido destacarse su cualidad de precursor éste es, precisamente, Aristóteles. Origen (e incluso, según Kant, clausura) de la lógica, padre de la biología, redactor del primer tratado de psicología... la filosofía de Aristóteles se ha descrito insistentemente como un antecedente privilegiado de quizá demasiadas ciencias. Conscientes del abuso contenido en estas estrategias de legitimación el presente trabajo tendrá por objeto subrayar, paradójicamente, la vigencia del pensamiento aristotélico en la psicología moral contemporánea. Más concretamente, nuestro propósito consistirá justificar que Aristóteles inauguró una comprensión de las pasiones que no habría de retomarse hasta la ilustración escocesa y que, sorprendentemente, se ha convertido en un paradigma dominante en la psicología contemporánea, a saber: la caracterización de las pasiones o emociones como procesos no sólo cognitivos sino también evaluativos.

La vigencia del pensamiento aristotélico en las ciencias experimentales no es un hecho que requiera demasiadas justificaciones. Anualmente se publican textos científicos en los que abundan menciones al filósofo de Estagira. Si bien, las más de las veces, estas referencias hacen de Aristóteles un mero antecedente remoto, no es extraño encontrar literatura en la que el pensamiento aristotélico se describe como un paradigma perfectamente vigente. Así, conocidos psicólogos como Barry Schwartz no han dudado a la hora de validar a Aristóteles como un interlocutor válido y como una inspiración perfectamente vigente y de hecho, un área de conocimiento naciente como es la psicología positiva ha establecido un fecundo diálogo con la doctrina eudaimonista de Aristóteles. En línea con esta apropiación contemporánea creemos que la aportación aristotélica al estudio de las pasiones no es un mero antecedente accidental sino que constituye una herramienta perfectamente útil a la hora de interpretar las pasiones en la psicología moral y que contiene algunas aportaciones singulares útiles para lo que la psicología contemporánea se conoce como Appraisal Theory o "teoría evaluativa» ${ }^{2}$. La teoría evaluativa (M. Arnold, R. Lazarus, N. Frijda) describe las emociones

${ }^{1}$ En inglés en el original: «The safest general characterization of the European philosophical tradition is that it consists of a series of footnotes to Plato".

${ }^{2}$ Lyons $(1980,73)$ hablará de teorías causal-evaluativas aunque en castellano la traducción preferente de este esquema se mantiene como «teoría evaluativa». 
como estados de conciencia que son consecuencia de una estimación valorativa y que requieren, por ello, el concurso de disposiciones psíquicas específicamente racionales. De este modo, toda emoción quedaría constituida por un juicio en el que el individuo evalúa una circunstancia dada como digna de compasión, vergüenza o ira. Esta teoría ofrece una alternativa cognitiva a los clásicos y obsoletos modelos fisicalistas como el de William James o Carl Lange al incorporar a las disposiciones emocionales una inherente carga evaluativa o judicativa. El paso de un esquema como el de James-Lange a una teoría cognitiva o evaluativa de las emociones adquiere una enorme relevancia en el ámbito de la investigación moral fundamentalmente por dos motivos. En primer lugar, las teorías cognitivas de las emociones invierten el esquema clásico en el que las emociones son consecuencia de una alteración fisiológica. Además, y éste es el rasgo tal vez más relevante para la filosofía moral, las emociones se describen como acontecimientos anímicos que requieren la intervención de complejos mecanismos cognitivos lo que habría de resignificar la tradicional oposición que, en nuestra tradición filosófica, se estableció entre la razón y las emociones. En este artículo trataremos de justificar cómo la psicología moral aristotélica se adecua a este paradigma contemporáneo de las emociones y el modo en que su filosofía moral se demuestra perfectamente coherente con dichos presupuestos.

\section{Razón o irracionalidad de las pasiones en Aristóteles}

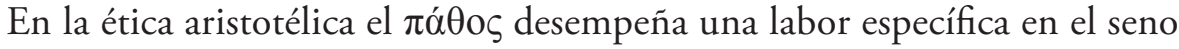
de la motivación moral toda vez que el deseo se distingue, tanto en De Anima ${ }^{3}$ como en sus Éticas, como un condición imprescindible para el movimiento de los seres vivos. Las pasiones son descritas como «una de las tres cosas que suceden

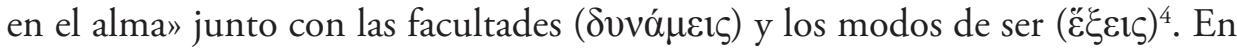
la Nicomáquea ${ }^{5}$ Aristóteles define las pasiones como aquello que «en general va acompañado de placer y de dolor» ${ }^{6}$ mientras que, más específicamente, en Ética Eudemia ${ }^{7}$ el filósofo matiza que las pasiones son «aquellas cosas que, por sí mismas ( $\kappa \alpha \theta^{\prime} \alpha v ̛$ đó), las más de las veces, van acompañadas de la sensación de placer

3 De aquí en adelante DA.

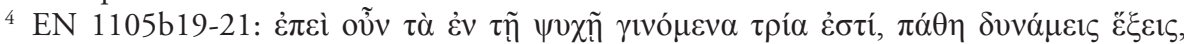

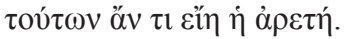

${ }^{5}$ De aquí en adelante EN.

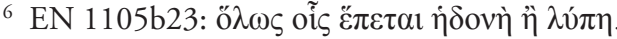

7 De aquí en adelante EE. 
y dolor» ${ }^{8}$. Este vínculo entre la sensación o percepción ( $\alpha$ ‘̋ $\left.\sigma \eta \eta \sigma \iota\right)$ ), la pasión y la acción - y que abordaremos con mayor detalle en las próximas páginasadquiere un claro significado a la luz de lo expresado en DA donde Aristóteles advierte que "cuando lo percibido es placentero o doloroso, la facultad sensitiva - como si de este modo estuviera afirmándolo o negándolo - lo persigue o se aleja de ello» ${ }^{9}$. Esta definición habrá de determinar, también, la interpretación aristotélica de las facultades y los modos de ser (i.e., de todo cuanto acontece en

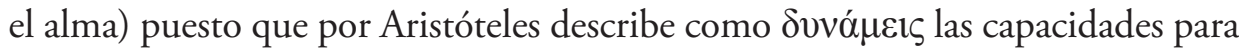
albergar pasiones y reserva el término $\check{\varepsilon} \xi \varepsilon 1 \zeta$ - recordemos, concepto central para la descripción de la virtud ${ }^{10}$ — para «aquello en virtud de lo cual nos comportamos bien o mal respecto de las pasiones» ${ }^{11}$.

Las pasiones dentro del esquema anímico de Aristóteles se asentarían naturalmente en la parte irracional del alma. Sin embargo, la concepción aristotélica del alma no puede resumirse en una mera escisión entre una parte racional y otra enteramente irracional sino que, entre uno y otro extremo, Aristóteles reconoce la existencia de una parte que siendo irracional «participa, de alguna manera, de la razón» ${ }^{12}$. Esta parte intermedia entre la razón y lo irracional es el lugar en el se asientan las pasiones lo hace posible que éstas, a pesar de no radicar en la parte enteramente racional, puedan participar, escuchar y obedecer a la razón. Su descripción a este respecto es clara y Aristóteles especifica que es tanto lo apetitivo

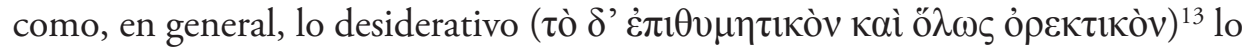
que participa de algún modo de la razón.

Esta primera determinación parece justificar, ya de inicio, un vínculo entre las pasiones y la razón en la medida en que el $\pi \alpha \dot{\theta} \theta$ o $\varsigma$ aristotélico adquiere la posibilidad de escuchar u obedecer a lógos. Esta caracterización, sin embargo, parece dibujar una relación puramente jerárquica entre un elemento rector: las pasiones pueden — desde un punto de vista ontológico — y deben — desde un

8 Arist. EE. 1220b12. En Rhet. presenta una descripción más inespecífica donde simplemente denomina pasiones a la ira, al apetito y otros semejantes». Rhet. 1378a19-22: ع̌ $\sigma \tau 1$

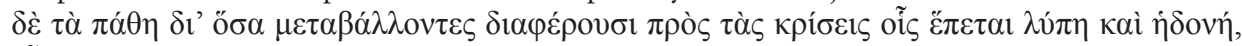

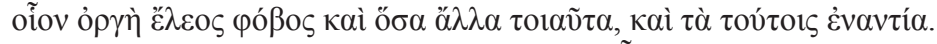

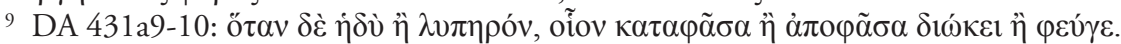

10 «Así pues, si las virtudes no son pasiones ni facultades, sólo resta que sean modos de ser».

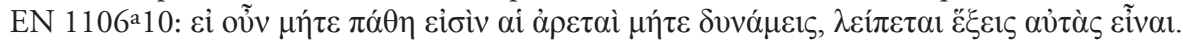

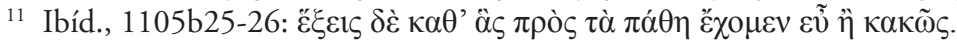

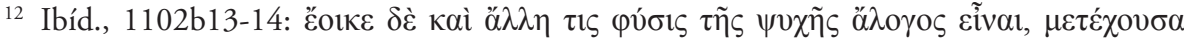

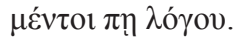

13 Ibíd., $1102 b 29$. 
punto de vista moral - secundar el dictado del lógos. Así, frente a la descripción de EN donde el carácter se describe simplemente como aquella cualidad del alma en virtud de la cual nos comportamos bien o mal con respecto a las pasiones ${ }^{14}$, en el texto de EE Aristóteles señala que ese comportarse bien o mal no consiste en otra cosa que en secundar el dictado de la razón puesto que «los modos de ser son las disposiciones causantes de que lo que hay en nosotros sea conforme o contradictorio con la razón» ${ }^{15}$.

Hasta el momento, parece innegable que las pasiones en Aristóteles no podrían descartarse como unos acontecimientos meramente irracionales si por irracional entendemos algo opuesto o contrario a la razón. En este sentido creemos poco afortunado el diagnóstico de R. Solomon quien, entre otras conclusiones exactas y pertinentes, no duda en situar a Aristóteles en el origen de lo que él mismo vino a bautizar como «el mito de las pasiones». Para este pensador, pionero en el estudio contemporáneo de las pasiones en filosofía, el pensamiento aristotélico se ubicaría en el origen de una larga tradición occidental que habría enfrentado la sabiduría de la razón con la tentación y traición (treachery) de las

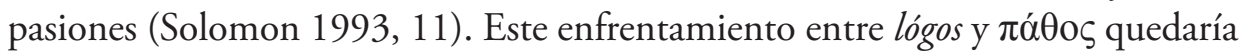
ejemplificado paradigmáticamente — siempre según Solomon — en las figuras de Aristóteles y Kant a quienes, acaso un tanto forzadamente, enfrenta otros autores como David Hume, John Stuart Mill o Bertrand Russell. Con independencia de la dudosa exactitud con la que esta dicotomía pudiera recrear las distintas actitudes que con respecto a las pasiones refleja nuestra tradición filosófica, parece más que justificado sustraer el nombre de Aristóteles de aquella relación de autores que Solomon denominara racionalistas ${ }^{16}$. De mano de las interpretaciones que durante las últimas décadas han realizado M. Nussbaum, D. Achtenberg, B. Zoziak, W.W. Fortenbaugh o J. Cooper, creemos pertinente asimilar la implicación del lógos en la determinación de las pasiones no como un rasgo adyacente o meramente adjetivo de la doctrina aristotélica sino como un rasgo distintivo y esencial del conjunto de su teoría moral.

Para Aristóteles el $\pi \alpha ́ \theta 0 \varsigma$ no es un mero instrumento auxiliar de la virtud sino que las pasiones adquieren una significatividad moral específica en la medi-

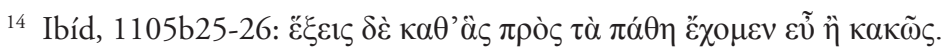

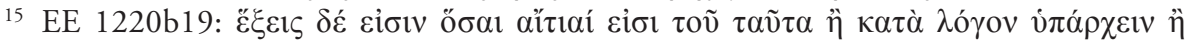

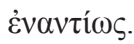

16 No tanto por ser «racionalistas» desde una perspectiva epistemológica moderna sino por

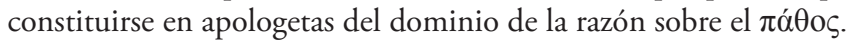


da en que, como ya señaláramos al principio de este texto, la virtud ética queda referida tanto a las pasiones como a las acciones. De hecho, la virtud es descrita no ya como una forma de acción concreta con arreglo a la disposición del lógos sino como una $\ddot{\varepsilon} \xi 1 \zeta$, esto es, como una forma de ser con respecto a las pasiones mismas. De este modo, y sea cuál sea el grado de subordinación o coordinación con el que Aristóteles prescriba la correcta disposición pasional, parece innegable que la doctrina moral expresada en EN y en EE dista mucho de otras planteamientos morales no menos influyentes como los de Cicerón o San Agustín, quienes al categorizar las pasiones como perturbationes animi ${ }^{17}$ evidencian, esta vez sí claramente, el enfrentamiento entre razón y pasión descrito por Solomon.

Desde una perspectiva general y conforme a la definición específica que Aristóteles nos brinda en sus éticas, ya hemos subrayado que, para el filósofo de Estagira -adoptando una postura no lejana de su maestro Platón-, las pasiones se ubican en una parte del alma que estando desprovista de lógos adquiere la posibilidad de escuchar y obedecer a la razón. Sin embargo, esta relación dista mucho de ser clara puesto que si sometemos su descripción general a un examen pormenorizado de las distintas formas de deseo (siendo el deseo un dispositivo inherente a toda pasión concreta) Aristóteles, nuevamente, vuelve a pronunciarse de un modo un tanto ambiguo. Si aspirásemos a reconstruir la descripción aristotélica del deseo de un modo coherente, la interpretación más sistemática y repetida sería, muy seguramente, aquella que pretende establecer una gradación de racionalidad en las distintas formas de la óp $\rho \xi ı$ (Cooper 1998, 241). Así, conforme a esta interpretación ya clásica, la غ̇đı $\theta v \mu i ́ \alpha$ se distinguiría por ser una

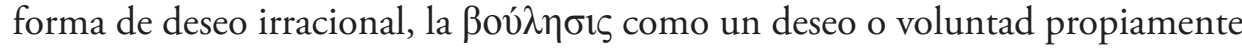
racional y el $\theta v \mu o ́ s$, de un modo un tanto ambiguo, se ubicaría en un nivel intermedio entre ambos extremos. Esta taxonomía, resumida con puntual detalle por John Cooper (1999, 342), ordena jerárquicamente los distintos deseos tomando como criterio la participación de la parte racional del alma en el deseo lo que

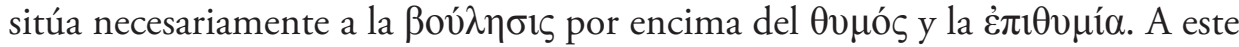
respecto, parece definitiva la claridad con la que el filósofo se expresa en DA

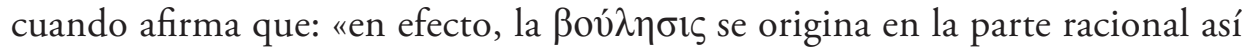

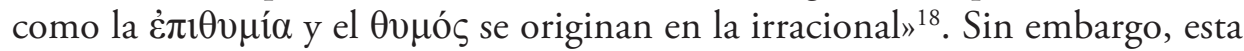

${ }_{17}$ Cic. Tusc. 3.7 y 4.10; Civ. 8. 17.

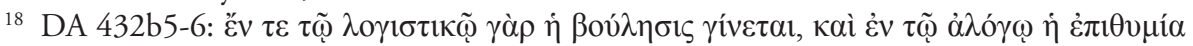

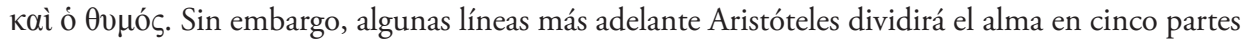
(nutitiva, sensitiva, intelectiva, deliberativa y desiderativa), lo que nos devolvería al problema de ubicar correctamente la ßov́ $\lambda\rceil \sigma \varsigma$ no ya en un esquema tripartito (como al que se hace referencia en 432b7) sino dividido en cinco partes. 
apreciación se encuentra del todo ausente tanto en EE como en EN, textos en

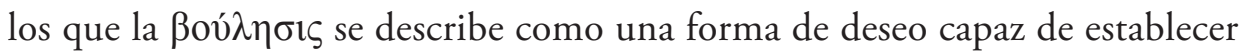
fines pero, al mismo tiempo, capaz de equivocarse ${ }^{19}$. Tal vez por ello, tratando de

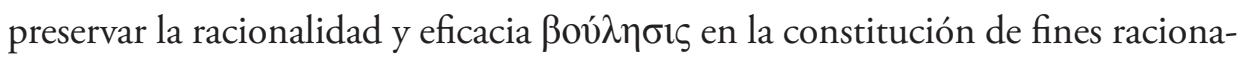
les, en el tratado psicológico Aristóteles describe el motor de la acción no como el objeto de la $\beta$ ov́ $\eta \sigma ı \varsigma$ sino, más genéricamente, como el objeto del deseo inespecífico ( $\tau$ ò ỏ $\rho \varepsilon \kappa \tau o ̀ v){ }^{20}$ puesto que se hace evidente que muchas acciones no son guiadas por la razón sino por el puro dominio de las pasiones. Éste es, probablemente, uno de los rasgos más determinantes a la hora de reconstruir el eventual enfrentamiento entre las pasiones y la razón y a partir del cual podríamos definir la cualidad y calidad moral de ciertas pasiones en Aristóteles.

A la luz de lo expuesto, constatamos que Aristóteles no censura el apetito sino, más precisamente, la desmesura o la apetencia de placeres indignos de la naturaleza humana. El riesgo no es, por tanto, el desencadenamiento de las pasiones

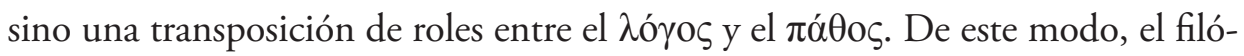
sofo insiste en la función rectora, tutelar y correctiva de la razón sobre el apetito subrayando, en tanto que posibilidad deseable, esa imbricación entre las pasiones y la parte apetitiva y pasional del alma. Por ello la doctrina moral aristotélica no propugna forma alguna de $\alpha \dot{\alpha} \alpha \dot{\theta} \varepsilon 1 \alpha$, ni tan siquiera veta el deleite de ciertos placeres corporales sino que lo que prescribe es una conveniente subordinación

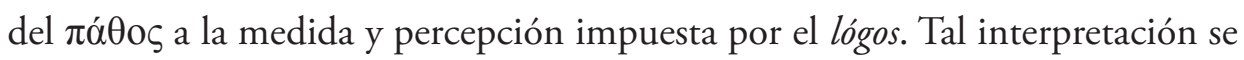
justifica en virtud de la doctrina del término medio y se expresa con claridad en las citas en las que Aristóteles advierte no ya de la negatividad de las pasiones sino de su dominio. El riesgo, por tanto, no es tanto albergar pasiones (ya que «es por naturaleza como tenemos esa facultad $»^{21}$ ) sino estar gobernado o dominado por ellas. Así, «tal es la condición de aquellos que están dominados por las pasiones, pues los accesos de ira, los apetitos de placeres amorosos y otras pasiones semejan-

19 A este respecto, y en referencia a las Éticas, creemos inexacta la apreciación de Cooper

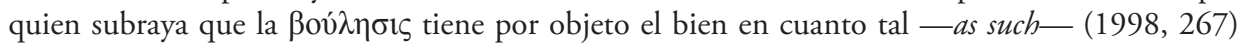
remitiéndose a EN. III.4. Esta interpretación podría resultar cabal en referencia a DA pero en EN

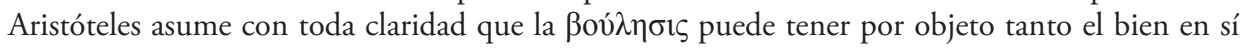
como el bien aparente. Cfr. Arist. EN. $1113 \mathrm{a} 25$ y ss.

${ }^{20}$ DA 433a20.

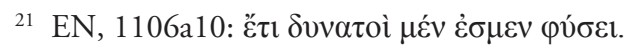


tes perturban, evidentemente al cuerpo $»^{22}$ y, como se señala en Retórica también pueden incluso corromper o modificar el juicio ${ }^{23}$.

A la vista de lo expuesto podría parecer que la subordinación del apetito y las pasiones a la razón se describe como una mera situación de control o límite. Tal es la interpretación que parecen sugerir las lecturas clásicas (Urmson, 1973) de la doctrina del término medio en Aristóteles en las que el lógos parece imponerse en dirección contraria a las pasiones mermando y limitando su alcance, operando como una exacta fuerza de contención. Creemos, sin embargo, que si tal hipótesis fuera cierta, nunca podría predicarse una implicación verdaderamente cooperativa entre la dimensión pasional y apetitiva del alma y la parte racional. Dicho de otro modo: asumir la relación entre el lógos y las pasiones como dos vectores de fuerza enfrentados impediría considerar cualquier implicación constitutiva - e incluso necesaria- de la razón en el desarrollo de las pasiones y dicha posibilidad, proponemos, es claramente defendida por Aristóteles al menos como posibilidad.

Esta lectura parece compadecerse fielmente con la distinción aristotélica entre los impulsos que proceden del razonamiento y aquellos otros que proceden del

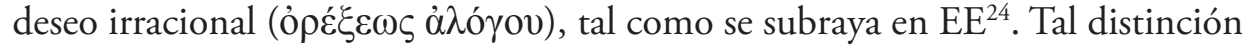
se ajustaría pertinentemente con la taxonomía del deseo suscrita por Cooper y justificaría el uso del término «irracional», tanto para calificar a la parte del alma en que se asientan las pasiones como para describir ciertas formas de deseo tales

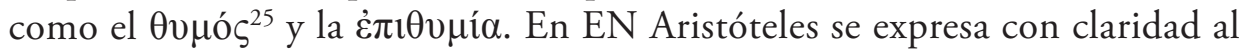
señalar que dos son las partes del alma, una racional ( $\tau$ ó $\lambda o ́ \gamma o v$ ) y otra irracional

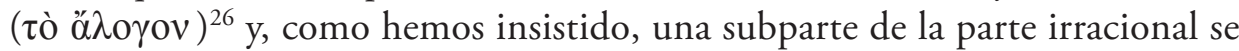
distingue por la capacidad de escuchar a la razón. Sin embargo, la relación entre la parte racional e irracional del alma no es simplemente una relación de seguimiento o subordinación sino que tanto en EE como en EN Aristóteles señala que

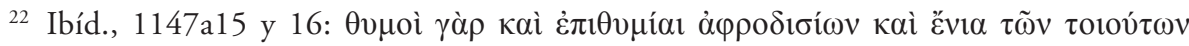

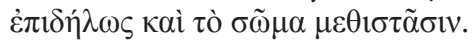

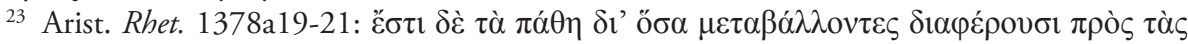

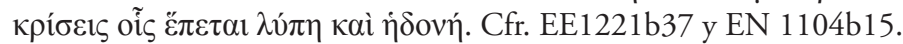

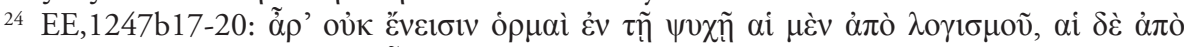

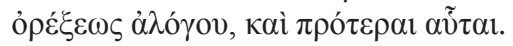

${ }_{25}$ En este sentido, calificamos al $\theta v \mu$ ó $\varsigma$ como una forma de deseo siguiendo la doctrina de J. Cooper según la cual cada una de las formas desiderativas que componen distintas formas de

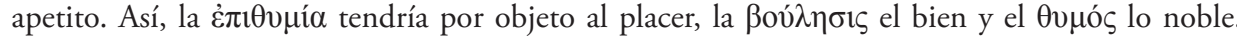
Reason and Emotion: Essays on Ancient Moral Psychology and Ethical Theory, Op. cit. págs. 266 y ss.

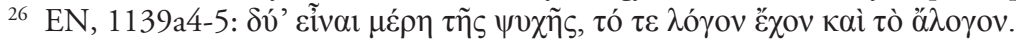


existe una forma de participación ${ }^{27}$ : «una parte del alma es irracional y la otra tiene razón $[\ldots]$. De lo irracional, una parte parece común y vegetativa [...]. Pero parece que hay también otra naturaleza del alma que es irracional, pero que participa, de alguna manera, de la razón $»^{28}$. A este respecto, el pasaje de EE resulta especialmente claro ya que si bien a una parte del alma le corresponde obedecer y a la otra escuchar, el de Estagira establece que dos son las partes del alma que participan de la razón, sin distinguir de modo explícito una parte racional y otra irracional. En este pasaje de EE, por tanto, la parte que fue designada como irracional en EN se asume de un modo un tanto indiferenciado junto con la parte que, podríamos denominar, estrictamente racional. Así, Aristóteles predica la misma cualidad de ambas partes (i.e., el participar de la razón) aunque, matiza, que esa participación no se da de la misma manera ${ }^{29}$.

La hibridación sugerida en EE entre las parte racional e irracional del alma y la referencia permanente a la función tutelar del lógos sobre la parte del alma donde se asientan las virtudes éticas parece sugerir una forma de relación que trasciende la mera subordinación o lo que, un tanto metafóricamente, describimos como una oposición vectorial de fuerzas enfrentadas. En el caso de que la razón operara frente a las pasiones (Hunt, Von Wright, Foot) o el deseo para ejercer de límite o contención externa parece improbable que pudiésemos suscribir una dimensión racional o cognitiva — según la expresión de D. Achtenberg- de las pasiones. Creemos justificado defender, como ahora argumentaremos, que la participación ${ }^{30}$ de la parte irracional de la psyché de la que habla Aristóteles no es simplemente un enfrentamiento entre facultades sino que la participación del lógos es un rasgo constitutivo de las pasiones. Esta participación constitutiva exigiría el concurso de la dimensión racional en la gestación de las distintas pasiones. La virtud aristotélica no se define meramente por ejercer un dominio direccional desde la parte racional del alma hacia la parte irracional sino que se define por la integración de la razón en la constitución de las pasiones como consecuencia de una educación adecuada basada en una coerción repetida que redundaría en la formación de un buen hábito.

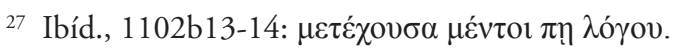

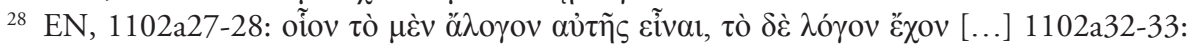

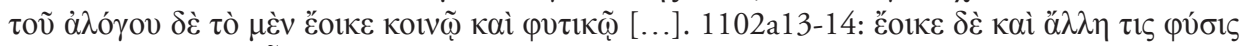

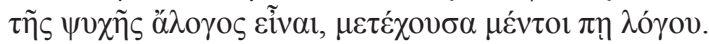

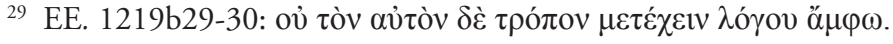

30 Para Fortenbaugh este uso del término participación ha de interpretarse como seguimiento $(1975,23)$. 


\section{Las pasiones como percepción estimativa}

Martha Nussbaum, en su excelente Upheavals of Thought - que no en vano lleva por subtítulo «la inteligencia de las emociones» ${ }^{31}$ - , toma como ejemplo el

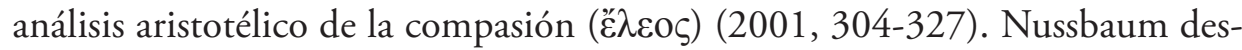
vela la dimensión cognitiva y evaluativa de la compasión en una interpretación análoga a lo que aquí hemos definido como relación constitutiva entre la razón y las pasiones. Siguiendo su interpretación - y asimilando el caso particular de la compasión ${ }^{32}$ a las demás pasiones destacadas en la relación aristotélica—, esta

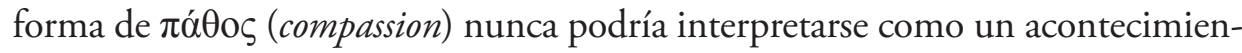
to puramente pasivo ni irracional sino que entrañaría consigo, al menos, tres elementos cognitivos. El primero de ellos es la evaluación o cómputo del daño que sufre la persona a la que compadecemos. De esta manera, no sentiríamos compasión al contemplar un sufrimiento trivial o ante un daño menor, como pudiera ser una pérdida fácilmente restituible. La compasión requiere, por lo tanto, una evaluación del daño y una reflexión en torno a sus consecuencias. De igual modo, y este aspecto ha tenido una especial significación en la historia de la filosofía (y más concretamente en la Poética de Aristóteles), la compasión sólo tendría lugar a partir de la analogía entre el individuo que sufre y la persona que compadece. Para que se suscite la empatía $(\sigma \nu \mu \pi \alpha ́ \theta \varepsilon i a)^{33}$ el observador debe reconocer una cierta semejanza entre aquel que sufre y su propia persona ya que, a partir de este parecido, podrá imaginar el daño ajeno como un sufrimiento posible en primera persona. Por último, y quizá este sea el contenido más interesante desde una perspectiva moral, la compasión es una pasión que requiere

31 Upheavals of thought. The Intelligence of Emotions. Cambridge (UK): C.U.P., 2001. Edición castellana se ha traducido como: Paisajes del pensamiento. La inteligencia de las emociones. Madrid: Paidós, 2008.

${ }^{32}$ La definición más completa de la compasión en Aristóteles la encontramos en Retórica: «Sea, pues, la compasión un cierto pesar por la aparición de un mal destructivo y penoso en quien no lo merece, que también cabría esperar que lo padeciera uno mismo o alguno de nuestros allegados, y ello además cuando se muestra próximo: porque es claro que el que está a punto de sentir compasión necesariamente ha de estar en la situación de creer que él mismo o alguno de sus

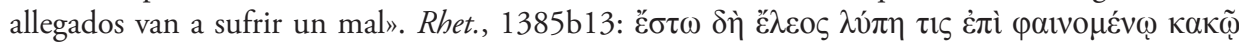

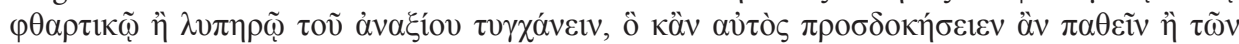

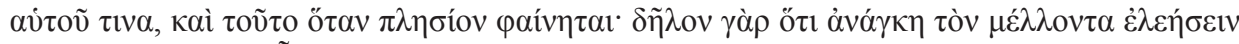

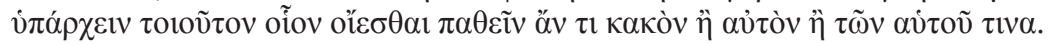

33 Aunque etimológicamente en castellano «simpatía» y "compasión» puedan parecer sinónimos, en griego se emplean dos vocablos distintos: ह̌̉ $\varepsilon_{0} \varsigma \zeta$ haría referencia a la compasión por sufrimiento, que en otras traducciones se identifica con piedad, misericordia... La $\sigma u \mu \pi \alpha ́ \theta \varepsilon \varepsilon 1 \alpha$ equivaldría a nuestra castellana empatía, a saber: la capacidad para ponernos en el lugar del otro y vivenciar, aunque de manera diferida, sus sentimientos en primera persona. 
una valoración del daño acontecido como inmerecido ${ }^{34}$. Por ello, para sentir compasión deberíamos haber evaluado al sujeto que sufre un daño y determinar si dicho sufrimiento es merecido o no.

Los tres elementos cognitivos aquí descritos demuestran el concurso de la razón no ya en la mesura o adecuación de una pasión determinada al objeto sino en su acontecer mismo. Es decir: toda forma de compasión requiere en su advenimiento un determinado proceso judicativo que le sirva de causa. Al igual que en su momento nos remitimos al pasaje del DA en el que Aristóteles vindicó la corporalidad de todas las funciones anímicas ${ }^{35}$, de la mano de Martha Nussbaum y atendiendo a la descripción que en la Retórica se realiza de la compasión, podemos comprobar el modo en que las pasiones, lejos de ser una inactividad o una afección puramente externa, requieren necesariamente la intervención de complejas disposiciones racionales para desencadenarse de modo correcto. De este modo, las pasiones no podrían comprenderse desde una perspectiva puramente irracional ni tan siquiera como meras afecciones. La intervención activa del sujeto en el cálculo, juicio y evaluación de la circunstancia que daría lugar al surgimiento de una pasión específica parece justificada a la luz de esta interpretación.

Podría objetarse, sin embargo, que este equipamiento racional no pertenece a las pasiones en general sino que tendría lugar, de un modo exclusivo, en el advenimiento de la compasión. Tal hipótesis no parece plausible ya que de cada una de las pasiones reseñadas por Aristóteles podríamos predicar una serie de dispositivos racionales que la asisten. Así, por ejemplo, la ira requeriría también una evaluación contextual que significara como injusto -al igual que en la compasión - un dolor infligido a un inocente lo que se traduciría en un deseo de venganza. De un modo semejante podríamos proceder en las demás pasiones: el miedo, la envidia, la alegría, los celos... — todas ellas descritas por Aristóteles como pasiones - dado que difícilmente podríamos imaginar su aparición si no situamos, en su origen, una operación racional que juzgue y evalúe un objeto o circunstancia como dignos de tales afecciones.

Vemos, por tanto, que la (recta) razón no ejerce simplemente como límite de contención o adecuación al término medio sino que, en Aristóteles — si acaso

${ }^{34}$ Esta evaluación moral acerca del merecimiento del daño resulta análoga a la descripción

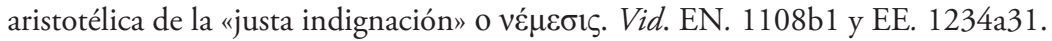

35 DA 402b5-10. 
no antes con Platón-, se erige como condición posibilitadora o constitutiva de las propias pasiones ${ }^{36}$ puesto que cierta intervención de la función razonadora se hace indispensable en la disposición de, al menos, algunas formas de pasión. Así, la ira se haría impensable sin una cierta forma de juicio o el miedo sería incomprensible si no se evaluara una circunstancia como potencialmente peligrosa. La estimación y valoración del contexto y la ulterior adecuación con la que dispongamos las pasiones al caso particular podrán ser más o menos ajustadas pero en el esquema aristotélico parece improbable que pueda desarrollarse una pasión sin un elemento judicativo o evaluativo. La función limitadora de la razón no

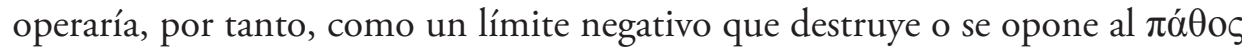
sino como un límite que opera en la constitución de las distintas pasiones De este modo, la utilidad de la razón trasciende su función tutelar o constrictora como Aristóteles matiza al exponer, precisamente, su doctrina del término medio. Indudablemente, dicho término medio se asume en términos cuantitativos (según el exceso o el defecto) pero la virtud ética se definirá no sólo como una disposición o tendencia a desarrollar pasiones conforme a una medida equilibrada sino a tenerlas «cuando es debido, y por aquellas cosas y hacia aquellas personas debidas, y por el motivo y la manera que se debe» ${ }^{37}$.

\section{Conclusión}

Podemos concluir, por lo tanto, que las pasiones en su conjunto ocupan un lugar privilegiado en la moral aristotélica en la medida en que son capaces de escuchar a la parte racional del alma. Desde luego, al hablar de posibilidad o capacidad nos estamos refiriendo a una forma de dýnamis contingente que, evidentemente puede — o no — ser actualizada. Esa capacidad de escucha, pese a todo, debe caracterizarse no como una mera subordinación posible sino como una estricta cooperación sin la cual, propiamente, no podría gestarse ninguna pasión o, al menos, ninguna distinta del deseo apetitivo. La razón es así un elemento constitutivo de las pasiones puesto que sin lógos no habría estimación de la realidad que nos permitiera distinguir (y este verbo no es casual) una circunstancia como digna de indignación, compasión o ira. La clave, por ello, no radica en la inclusión o no

36 En una dirección inversa, que abordaremos más adelante, la neurociencia contemporánea establecerá, como señala Patricia Greenspan, una función posibilitadora (enabling function) no ya desde la razón a las emociones sino desde las emociones al razonamiento. Vid. The Oxford Handbook of Rationality. NY: OUP, 2004, pág. 174.

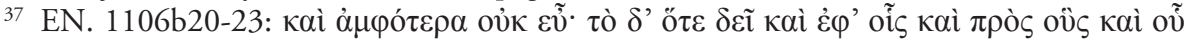

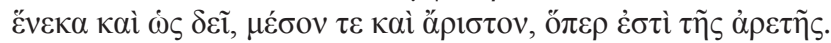


de dispositivos racionales en el desencadeniamiento del lógos sino en su cualidad adjetiva. Así, Aristóteles a la hora de caracterizar su ideal ético en la disposición de las pasiones requerirá no sólo el concurso de «la razón» sino que exigirá que esa razón sea efectivamente recta, esto es, ỏ $\rho \theta$ ò $\varsigma \lambda$ ó $_{0} \varsigma^{38}$. Sin embargo, las pasiones - descritas, recordemos, como aquello que va acompańado de placer- no pueden caracterizarse como una mera síntesis de racionalidad y sensación de placer sino que la constitución perceptiva de una actividad como placentera requiere, ya de inicio, la intervención de la parte racional del alma -al menos, sin duda, en el

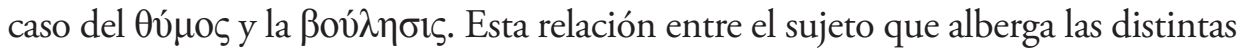
pasiones, la realidad externa que motiva su acción y la adecuación entre ambos extremos son las condiciones que nos permiten afrontar la dimensión perceptiva de las pasiones y su consiguiente capacidad cognitiva.

A la luz de lo expuesto creemos que la interpretación aristotélica de las pasiones resulta perfectamente coherente con el paradigma dominante en la neurociencia y en la psicología contemporánea. Este hecho, más allá de ser una feliz casualidad, es sin duda es un motivo más para reivindicar la vigencia del pensamiento moral aristotélico y su utilidad en contextos no específicamente filosóficos. El crédito y la dignidad del legado aristotélico jamás habría de depender de su consistencia con la ciencia contemporánea que, por lo demás, es suceptible de futuras falsaciones. Sin embargo, a diferencia de otras áreas puramente teoréticas de nuestra disciplina, la filosofía práctica ni puede ni debe dejar de atender a aquellas conclusiones que nos brindan las ciencias positivas. $\mathrm{Si}$, como señalara Kant, el debo ha de ser siempre deudor del puedo, la ética habrá de atender con detalle a todo cuanto la ciencia pueda explicarnos acerca de la conducta humana, de sus límites y sus motivaciones. Con el presente artículo no pretendemos significarnos como unos apologetas del neoaristotelismo ni concederle al de discípulo de Platón un especial mérito predictivo. No podemos considerar a Aristóteles como un precursor de las teorías evaluativas de las emociones puesto que no podemos reconstruir una secuencia causal que vincule la investigación contemporánea con las doctrinas heredadas del pensador de Estagira. Sin embargo, en el inevitable ejercicio de recepción crítica de nuestra historia del pensamiento la ética aristotélica vuelve a reivindicar su vigencia a partir de su compatibilidad con la teoría evaluativa o cognitiva de las emociones y representa un hito singular en nuestra tradición filosófica que, en demasiadas ocasiones, ha sido malinterpretado. En la segunda mitad del siglo XX el ocaso de algunos paradigmas morales rivales como el deontologismo kantiano o el utilitarismo favoreció una

${ }^{38}$ EN, 1114b29; Cfr. EN 1119a20 y EE1222b7. 
restitución la filosofía práctica aristotélica y, partir de lo expuesto en este trabajo, confiamos en sumar a la prolongada relación de argumentos favorables un nuevo motivo para hacer de la filosofía práctica de Aristóteles un recurso válido en nuestro tiempo. Con ello no queremos defender un artificial apropiación in toto de la teoría moral aristotélica sino validar, precisamente como un interlocutor vigente, al viejo pensador de Estagira.

\section{Bibliografía}

\section{Aristóteles:}

Ross, W.D. (1956, 1963). De Anima, Oxford: Oxford Classical Texts.

Suseminl, F. y Apelt, O. (1912). Ethica Nicomachea, Oxford: Oxford Classical Texts.

Walzer, R.R. y MingaY, J.M. (1991). Ethica Eudemia, Oxford: Oxford Classical Texts.

\section{Traducciones:}

1978. Acerca del alma (Tr. Tomás Calvo). Madrid: Gredos.

1959 [2002]. Ética a Nicómaco (Tr. María Araujo y Julián Marías). Madrid: Centro de Estudios Constitucionales.

2002. Ética Eudemia (Tr. Carlos Megino). Madrid: Alianza.

1994. Retórica (Tr. Quintín Racionero). Madrid: Gredos.

Achtenberg, D. (2002). Cognition of value in Aristotle's Ethics. Albany: State University of N.Y. Press.

Arnold, M. B. (1960). Emotion and personality. New York: Columbia U. Press.

Cooper, J. (1999). Reason and Human Good in Aristotle. Princeton: Hackett Publishing Company.

Fortenbaugh, W.W. (1975). Aristotle on Emotion. London: Duckworth.

Konstan, D. (2007). The Emotions of the Ancient Greeks. Toronto: U. of Toronto Press.

Lazarus, R. S. (1991). Emotion and adaptation. New York: Oxford U. Press.

Lyons, W. (1980). Emotion. Cambridge: Cambridge U. Press.

Prinz, J. (2006). The Emotional Construction of Morals. New York: Oxford U. Press.

Gross, D. M. (2006). The Secret History of Emotion: From Aristotle's «Rehtoric» to Modern Brain Science. Chicago: U. of Chicago Press. 
Nussbaum, M. (1996). The Therapy of Desire. Princeton: Princeton U. Press.

- (1996). The Therapy of Desire. Princeton: Princeton U. Press.

- (1998). Reason and emotion. Princeton: Princeton U. Press.

- (2001). The fragility of goodness. Cambridge (MA): Cambridge U. Press.

- (2003). Upheavals of thought. Cambridge (MA): Cambridge U. Press.

Solomon, R. C. (1993): Passions, Indiana.

Urmson, J. O. (1973). "Aristotle's Doctrine of the Mean», American Philosophical Quarterly 10: 223-30.

Recibido: 7/09/2012

Aceptado: 11/01/2013 